\title{
Textual Functions of the English Verbal Group
}

\author{
Roseline Abonego Adejare \\ Department of Language, Arts and Social Science Education, Lagos State University \\ PMB 0001, LASU Post Office, Badagry Expressway, Ojo, Lagos, Nigeria \\ E-mail: abonego@yahoo.com
}

Received: November 26, 2012

Accepted: December 18, 2012

Published: December 20, 2012

doi:10.5430/elr.v1n2p153

URL: http://dx.doi.org/10.5430/elr.v1n2p153

\begin{abstract}
The description of the English verbal group has primarily focused on its formal elements, whereas natural language is form and situation. This paper exemplifies some of the textual functions of the verbal group using data from spoken instructional texts recorded in selected secondary schools in Lagos, Nigeria. Four subjects (Christian Religious Knowledge, Geography, Physics and Chemistry) and four teachers were involved in the study. The corpus size was 17 600 words and the data comprised 3069 verbal groups. Each verbal group was carefully examined to determine its textual function(s) using situation-induced elements of natural language. Twenty-seven textual functions (e.g., describing entities) were identified. Present tense, $B E$, and imperative mood respectively expressed 74, 56 and 41 per cent of the functions. Although there was function overlap, this study has confirmed the fact that the formal features of the verbal group currently known grossly under-represent its textual functions in natural language.
\end{abstract}

Keywords: Textual functions, Verbal group

\section{Introduction}

The description of the English verbal group (VBG) has primarily focused on the functions of its formal elements in line with the atomism of 'language is form' (Hyelmslev, 1943) of 20th century linguistics derived from Saussure's 'form' is the linguistic norm, whereas natural language is form and situation (Adejare, in press). As extensively proved in Adejare (in press), Saussure's legacy of 'language is form' atomism creates inaccurate descriptions of both linguistic form upgraded into language and their functions, even when limited to only formal functions and not extended to the textual functions of natural language. This paper exemplifies some textual functions of the English VBG, the grammatical unit that realises the only obligatory element of clause structure predicator, using data from spoken instructional texts produced by teachers in direct face-to-face classroom contacts. The paper is a follow-up of a larger grammatical study of the English VBG (Adejare, 2010).

The VBG is the most studied aspect of the grammar of English (Palmer, 1987), but there is a dearth of studies on its textual functions. What exists as descriptions of the VBG functions, whether of the entire group or aspects of it, are descriptions of its formal functions (grammatical and semantic). For example, descriptive statements that point to the fact that the VBG "functions primarily as the predicator in the English clause structure" (Adejare \& Adejare, 2006, pp.162), the "English present tense... signifies present time" (Quirk et al. 1985, pp. 175), and the passive "allows the agent to be omitted" (Palmer, 1987, pp. 83) refer to formal functions only. Similarly, the thirteen meanings of BE ( e. g., to exist; to happen or occur) described using the same data as that for the current study are viewed as manifestations of its formal functions only(Adejare, 2012); they contrast sharply with its textual functions as will be seen in this current study. Yet attention has to be paid to the VBG and its textual functions because of its significance in language use.

\section{Background}

To date language function analyses have been limited to form. This affects even pragmatics and systemic functional grammar, formal models attempting with limited success to describe natural language texts. This section critically reviews some of the approaches to the analysis of natural language form and functions.

\subsection{Formal Semantics}

Formal semantics identifies the descriptive (propositional), expressive (non-propositional), and social (social relations) functions of language (Lyons, $1977 \&$ 1981). These functions are formal and therefore exclude natural language functions exemplified, for instance, by teachers' use of the VBG. Moreover, analysis takes the form of defining the verb lexeme without paying attention to situation and without accounting for other constituents of the VBG. Since the 
VBG operates as a syntactic whole, it amounts to descriptive atomism to simply isolate the verb lexeme from the rest of the VBG where there are two or three elements of group structure present. It further confirms formal semantics' lack of capacity to handle natural language data (Lyons, 1981, pp. 174).

\subsection{Pragmatics}

Because pragmatics sees language as an integral part of social interaction (Lyons, 1977; Fromkin \& Rodman, 1983) and studies how context affects the interpretation of utterances, it is often assumed to account for natural language data. However, its notion of context is formal (Atkinson et al., 1982, pp. 203 ). Again, illocutionary act, the central object of study of pragmatics, lacks textual relevance. First, it is not concerned about whether or not an utterance produces the intended change in the hearer. Second, statements, questions and commands, which are its major components, are too broad. For instance, in spoken instructional texts a text encoder does not merely issue an order; he does so with an underlying goal which must be identified and accounted for in any serious study of natural language function. Moreover, analysing language function in terms of conventional implicatures and conversational implicatures alone, described by Hall (2005, pp. 201) as "pragmatics par excellence", is inadequate. As seen in Olaniyi (2010, pp. 59), pragmatics makes only a weak reference to grammar. It has the wrong notion that "all description is strictly a terminal process" aimed to save languages, not by describing them, but "by saving their users" (Mey, 2001, pp. 15). This study is concerned with the textual functions of the VBG, a unit of grammatical description which pragmatics cannot handle because it excludes natural language situation from its framework.

\subsection{Functional Grammar}

Functional grammar identifies the ideational, interpersonal and textual functions of language (Halliday \& Matthiessen, 2004). The ideational metafunction deals with how language is used in the organisation, perception and comprehension of the world. Its experiential component is concerned with ideas, while its logical component deals with their organisation. The interpersonal metafunction enacts interpersonal relationships that are supposed to deal with how language is used in acts of communication. The textual metafunction relates the ideas expressed in both the real world and other linguistic events. The three metafunctions contribute separately but simultaneously to the structure and meaning of the clause; they are however represented "as partial contributions to a single structural line" in respect of the group (Halliday \& Matthiessen, 2004, pp. 309).

With particular reference to the VBG, Halliday and Matthiessien (2004, pp.335-54) formalise its experiential structure as "Finite plus Event and Polarity". The Finite relates "the process to the "speaker now" " by tense or modality, and the Event expresses a process using the verb lexeme. The logical structure is realised by recursive tense, while the interpersonal and textual functions are handled together with the experiential meaning at once. The systems are linked to the functions through secondary tense (deriving from logical function), aspect and event (deriving from experiential function), polarity, finiteness and modality (deriving from interpersonal function), and voice, contrast and ellipsis (deriving from textual function). Mood and transitivity are said to belong to the clause.

These descriptions pose a number of problems. First, as Halliday and Matthiessien (2004, pp. 168) declare, the three metafunctions are bound to the clause and are therefore formal functions. Second, the taxonomic, pattern drill-like analysis (see Opeibi, 2010, pp. 250-54) merely assigns functional labels to items without demonstrating how each component contributes to the overall meaning of its text as a communicative unit. Third, the metafunctions fail to indicate what other functions is in, for example, Air is a mixture of gases, may also express outside present tense and Finite/predicator. An analysis of the textual function(s) of is in Air is a mixture of gases, ought to, at least, state the fact that it defines air, with its formal functions taken as given. Fourth, most texts analysed are hardly above paragraph length and there are no clues on how to handle large texts, such as the transcript of a 40-minute lesson (cf. Bloor \& Bloor, 1995). Functional grammar has no relevance for this study because the systemic model, while recognising situation as an element of language, excludes it from its linguistics, as made explicit in Halliday et al.(1964, pp.18).

\subsection{Natural Language Theory}

This study adopts a holistic natural language theory which recognises form and situation as the two primary elements of language (Adejare, in press). Unlike 20th century linguistics which suffers the limitation of stopping only at formal meanings, natural language theory gives a better perspective of both the form and textual functions of language. Predicating this work on natural language theory would enable a fuller account to be made of the textual function(s) of each VBG in relation to its text's message, defined here by the subject matter, and in terms of its contributions to the projection of that message. 


\section{Method}

\subsection{Participants}

In the original research, eighteen graduate teachers (in four secondary schools in Lagos State, Nigeria), eight subjects (including English, Biology, History and Mathematics) and thirty-two lessons were initially involved. The subjects were chosen because they were taught in English. There were other considerations too. For instance, Islamic Religious Studies was excluded because of its heavy Arabic content. The teachers were selected on the basis of their being the regular teachers for the subjects. However, after transcribing all the tapes, marking the clauses, and identifying and numbering all the VBGs therein, a data yield of over 24,000 VBGs was considered enormous and unwieldy. This necessitated pruning the data base, having profoundly considered factors such as the Humanities/ Science balance, relative popularity of subjects, and audio quality of tapes. Four senior secondary subjects and their teachers were finally selected. The subjects are Christian Religious Knowledge, Geography, Physics and Chemistry. The topics taught were respectively The Mission of the Church, The Drainage System, Electric Field, and Nitrogen.

\subsection{Instruments}

Tape recording and observation served as data collection instruments. The lessons were personally recorded and observed during the normal periods for the subjects between June and November 2002.

\subsection{Procedure}

The four lessons lasted approximately 196 minutes. The size of the corpus was 17600 words and 3069 VBGs constitute the data for the study. Each VBG was carefully examined in its clause context to determine its textual function(s) in relation to the subject matter. All the textual functions of the VBG, and the VBGs expressing them, were separately identified. The scale-and-category version of the systemic grammatical model (Halliday, 1961), complemented by simple percentages, aided the preliminary analysis of data.

This preliminary analysis of data revealed some facts that are pertinent to the current study, which are summarised as follows: The H-Type VBG was dominant (1 822 or $59 \%$ ), and its $\mathrm{x}+0$ and $\mathrm{x}+\mathrm{s}$ morphological variants accounted respectively for $32 \%$ and $38 \%$. (The symbol x represents the verb lexeme; 0 after + denotes the absence of a verb inflection while $s, g, d$, or $n$ stands for the presence of a particular inflection.) The MH-Type, HQ-Type, and MHQ-Type structural variants accounted respectively for $31 \%, 7 \%$ and $3 \%$. $B E$ was the most recurring verb lexeme; it accounted for $24 \%$ ( 728 VBGs) of the data, occurred 41 times in 1000 words, and was dominated by is (65\%). Tense represents $71 \%$ ( $2183 \mathrm{VBGs}$ ) of the data, with its present, past and future forms accounting respectively for $72 \%, 20 \%$ and $8 \%$. Aspect ( 270 or $9 \%$ ), modality (383 or 13\%), imperative mood (221 or $7.4 \%$ ), interrogative mood (310 or 10\%), passive voice (304 or 10\%), and to-non-finite form (99 or 35\% of nonfinite) featured as indicated in brackets.

Twenty-seven textual functions were identified based on a critical examination of the texts analysed. The textual functions and the variety of VBGs expressing them are displayed in Table 1 below.

\subsection{Textual Functions Exemplified}

Before illustrating the twenty-seven textual functions of the VBG identified in the texts, it is important to point out the fact that giving orders does not form part of the list because, as shown in Table1, and as will be further demonstrated in-text, VBGs marked for imperative mood which indicated order as an underlying semiotic function were also associated with several other textual functions. In the presentation that follows each textual function is accorded a separate heading for recognition and differentiation purposes. Listed examples are followed by the source text's code (R, G, P and C for Christian Religious Knowledge, Geography, Physics and Chemistry respectively) and the VBG's number. Similarly, excerpts are preceded by the source text's code, the letter K for clause, and the clause's number (e.g., PK5), with the VBG under focus marked and its number enclosed in brackets. Because of space constraints one excerpt will suffice, except where the textual function illustrated dictates otherwise.

\subsubsection{Introducing the Lessons}

$B E$ - and want-headed, and will- and $B E$ GOING TO- modified, VBGs served to introduce the lessons. With the exception of $B E$ which introduced the topic by defining it, all the VBGs semiotically indicated intention (e.g., want to look at R2).

[1] PK2 So today we are going to talk about (2) electric field. K3 Electric field is (3) a region where a charged body experiences a force. 


\subsubsection{Transiting from one Segment of the Lesson to another}

Present tense VBGs manifesting the $\mathrm{x}+\mathrm{s}$ form H-Type variant (takes R525; leads P11), VBGs marked for imperative mood (see let talk about P411 in [8] below), and some indicating interrogative mood (see [10] below), functioned to transit from one segment of the lesson to another.

[2] RK415 So that's all about the activities of Philip in Samaria, K416 which takes (525)...us on to something else... (cf.PK7 And this leads (11) us to Coulomb's law))

\subsubsection{Ending the Lesson}

The $\mathrm{x}+0$ form H-Type VBG and $B E$ were used to conclude the lessons. However, VBGs marked for imperative mood ended specific class activities.

[3] RK106 Let's stop (135) there for a moment...RK 624 So we see (781) next lesson, okay? K625 Have (782) a nice day.

3.4.4 Summarising, Recapitulating, or Concluding a Point

$B E$ and $\mathrm{x}+\mathrm{s}$ form H-Type VBGs were used in summarising, recapitulating, or concluding a point. They almost always collocated with the summative conjunct $s$.

[4] PK360 So that means (393) that the resultant force is four point one two times ten raised to power eleven Newton... K417 So that is (443) the value.

\subsubsection{Emphasising, Reiterating, or Reinforcing a Point}

To emphasise, reiterate, or reinforce a point, say- and tell-headed VBGs, and $B E$ in polar interrogative clauses, were used. Repetition of negated forms also featured.

[5] CK 477 As I told (517) you before, K478 once you are a chemist ...K583 Oxygen is a good oxidising agent.

K584 Am (636) I correct?

[6] RK567Did Jesus open his mouth? (R: No).K568 He didn't say (707) anything. K574 Even when they pounced on him, K575 he didn't say (716) anything.

\subsubsection{Enumerating Points}

Verbal groups used in enumeration differed according to what was enumerated. Points to be discussed and points already discussed were expectedly coded using VBGs marked for future tense (will look at C211 in [7]) and perfective aspect ( have found $\mathrm{P} 313$ in [8]) respectively. Facts on the topics taught were however listed using present tense, $B E$ and perfective aspect (is R452; have taken $\mathrm{R} 467$ in [9]).

[7] CK173 What are the things we are going to look at concerning nitrogen generally? K174 We are going to look at (198) the occurrence of nitrogen...K177We are going to look at (201) manufacture...K187Finally, we will look at (211) the uses of nitrogen.

[8] PK379 So we'll talk about electric field intensity. K380 So far we have discussed (408) the force between two charges and K381 we've defined (409) Coulomb's law...K384 So let's talk about electrical intensity.

(Enumerating points to be discussed was sometimes immediately followed by points already covered or vice versa. Verbal groups used in transiting and enumerating literally in the same breath enhanced textual cohesion, e.g., ' $l l$ talk about and let talk in [8] above.)

[9] RK 342 What kind of signs are we talking about? ...K348 Demons were cast out of them. K349 That is (452) one... K351 The lame could walk ...K365 You have (446) the working of miracles...K366 We have taken (467) three ...K404 So these are (514) the six ways the Holy Spirit manifested his activities in Samaria.

\subsubsection{Asking Questions}

Questions were expectedly asked using VBGs in indicative interrogative mood. $B E$ - headed and $D O$-modified forms were prominent. Uniquely non-finite forms featured in echo questions used as technique for revising taught processes, e.g., CK731 To remove (773) what?. Questions served more specific purposes such as transiting from one segment of the lesson to another ([10]), introducing new terms and concepts ([11]), stimulating comprehension and testing recall ([12]), and sharpening pupils' power of imagination and introspection ([13]). Here are the excerpts.

[10] RK421 But when Philip left Samaria, K422 what was (533) his next destination? K423 Where did he go (534)... K425 And who directed (537) him? K426 That's what we want to find out now. 
[11] GK12 How do you discover ... the particular drainage pattern that we are discussing? K13 Is (16) it trellised? K14 Is (17) it centripetal? K15 Is (18) it radial? K16 Is (19) it dendritics? K17 Is (20) it centrifugal ? K18 Is (21) it bar bed? [12] RK476 So what happened (592) from that point?... K479 Who was (595) this Ethiopian Eunuch? ...

K499 What was he doing (617)? (R: He was reading)...K501What was he reading (619)? (R: He was reading about Prophet Isaiah)

[13] RK533 We read abi 32 and 33...K536 Okay, who do you think (662) that passage was referring (661) to? K537 You don't understand the passage we read. K538 Like a sheep meant to be slaughtered. K539 That was talking about Jesus Christ.

Other macro functions of the VBG expressing question as a primary textual function are sharpening pupils' evaluative judgement (does it mean G139) and deductive (e.g.GK424 What is (477) the significance of River Odo here?) skills, predicting relationships (PK182 Is it going to be (202) attraction or repulsion )) or outcomes (e.g., CK602 What will happen (662)), reinforcing a point (see Am I correct in [5] above), and determining whether or not the lesson had been understood (CK 95 Do you understand (112)?)).

\subsubsection{Describing Entities}

Verbal groups used in description varied according to the entities described ( states, actions, processes, events, persons/people, places, directions and locations, concepts, things, and relationships), although it was not uncommon to find the same forms recurring, as the illustrations that follow show.

States

Tense, lexical $B E$ and aspect recurred in the description of states. The choices however depended on the state described. Perfective aspect was associated with resulting state (e.g., [14]), whereas present and past tense forms indicated psychological state (e.g.[15]), current state ([16]), past state, and state of knowledge. Here are some examples.

[14] GK150 The river... has matured (176).

[15] RK44 And fear came upon (55) the Church generally. K45 They were (56) so afraid. K46 Nobody was (57) certain any more.

[16] PK221 $K$ is (237) still nine times ten raised to power nine. ( $K$ ‘s value is constant in a given equation.)

Actions

Verbal groups marked for progressive aspect dominated the description of actions. The specific actions described and the VBGs used are motional actions (of persons, e.g., started running R406; the river, e.g., is flowing G340; electric current, e.g., is being pulled P712; vehicles, e.g., is moving P699; and electrons, e.g., is reacting C81), articulation actions (e.g., tell P272), literacy-related actions (e.g., was reading R619), mental actions ( e.g., start solving P685 ), and miscellaneous actions (e.g., heat C786). Two excerpts will suffice.

[17] GK103The river is eating(110) deeply into the soil...K288The river is meandering (331).

[18] PK 665 As $\mathrm{q}_{1}$, as the negative is pulling (742) the test charge...K671 the positive will be moving (742) this way.

Processes

The processes described and the forms used are baptismal processes (passives, past tense), problem solving processes (imperative mood, modality: necessity), the abrasion process (progressive aspect), ox-bow lake formation processes (perfective aspect), and processes in the industrial and laboratory preparation of nitrogen (present tense). The first two are illustrated as follows.

[19] RK211 Because it was baptism by immersion, K212 they were only put (270) in water and K213 they were brought (271) out.

[20] PK452 You first of all have to change (474) the unit of distance... K454 So, since it is in centimetre, K455 take (478) it to metre... K485 So, remove (522) this denominator, K486 bring (523) it up as numerator ...K490 Add (530) everything together.

Events

Verbal groups marked for past tense featured in the description of events, a textual function that manifested only in Christian Religious Knowledge because of the historical nature of the topic taught. Four events were described thus: the persecution following Stephen's death (e.g., arose 154), Philip's journey to Samaria and his activities there (e.g., 
started preaching 139), Simon's conversion (e.g., bowed 215), and the Ethiopian Eunuch's baptism (e.g., baptised 757). Excerpt [28] illustrates.

[21] RK598 And we were told that as he went along, he came near a stream. K599 What happened?...

K602 And immediately they came down (756) from the chariot, and K603 Philip baptised (757) him.

Persons / people

The description of persons/people occurred only in Christian Religious Knowledge, and it was achieved using $B E$, present tense, passives, and progressive aspect. The persons/people described and the specific VBGs used are Stephen (e.g., was called 49), Simon (was 200), Jews (e.g., see 233), non-Jews (is236), the Ethiopian Eunuch (e.g., was working 598), and Jesus (was 672). Excerpt [22] illustrates.

[22] RK181 They see (233) themselves as a superior race ... K183 and any other person outside the Jewish race is (236) unclean and $\mathrm{K} 184$ is regarded (237) as a gentile ...

Places, directions and locations

Places were described using lexical $B E$ in present tense form, directions using the $\mathrm{x}+\mathrm{g}$ non-finite form and progressive aspect (e.g., linking G435, leading R580, moving P698, is coming C105), and location using BE and the $\mathrm{x}+\mathrm{g}$ non-finite form ( is R544, carrying G321\& 438). As examples [23]-[25] respectively show, VBGs describing places, directions and locations collocated with the adjectival, prepositional or adverbial group.

[23] GK378 Because the place is (419) swampy.

[24] PK 631 Now think back to what you did under vectors.K632 I did tell you that if you have two vehicles moving (698) in the same direction...(cf. CK88 So if another hydrogen is coming (105) here))

[25] RK436 It's (548) in Africa.

Concepts

Verbal groups used in describing concepts tended to be paraphrases of the concepts described (see [26]). Four concepts were described as follows: martyr ( died R50; believed in R51), low and high tide (is G490), electric field (can be P14; is P15), revertible electrons (can give out $\mathrm{C} 46$ ), and liquefaction (liquefy $\mathrm{C} 368$ ). The last one is illustrated below.

[26] CK 38 From the look of things nitrogen is having five revertible electrons. K39 That is, nitrogen can either give out (46) five electrons or what? K40 or it can take (48) K41 it can gain (49) three electrons

Things

The $\mathrm{x}+\mathrm{s}$ H-Type present tense VBG dominated by $B E$ recurred in the description of things. This is evident in the description of the properties of nitrogen below:

[27] CK189 Nitrogen occurs (212) abundantly in the atmosphere...K193It is (216) relatively inert... K196 It doesn't react (220) easily...K199 It is (223) colourless, odourless and K200 it is (224) neutral to litmus...

K202 It is (226) ehm almost insoluble in water.

Relationships

Modals of prediction co-occurring with relational verbs (e.g., will repel $\mathrm{P} 689)$, BE (e.g., was R298), the $\mathrm{x}+\mathrm{s}$ present tense form (equals P32, determines P617) and the $\mathrm{x}+\mathrm{g}$ non-finite form (breaking R241) described relationships. Excerpt [28] illustrates.

[28] PK278 Force and electric field are (311) examples of a vector quantity ...K557 Now, what happens (620) at P determines (619) the kind of resultant...K626The negative q will attract (688) the test charge, K627 the positive q will repel (689) the test charge.

\subsubsection{Defining or Introducing New Terms and Concepts}

Verbal groups used in defining or introducing new terms and concepts were headed by call (18), BE (16), say (8), refer (5), know (3), mean (3), state (2), HAVE (2), give (2), regard (1), and name (1). They were morphologically $\mathrm{x}+0$ (25), $\mathrm{x}+\mathrm{s}(17)$, and $\mathrm{x}+\mathrm{n}(16)$ and syntactically H-Type and MH-Type. Moreover, they were either marked for simple present tense (42), passive voice (16), past tense (2), or progressive aspect (1). Sixty-one VBGs served this function. Here are examples. 
[29] GK102 Secondly, it has what they call (109) vertical erosion. K103That is, the river now is eating deeply into the soil through a process called (112) corrasive erosion...K254 Such a system is known (296) as abrasion process.

[30] CK286 Air is (316) a mixture of gases...K759 Pyrogallol is (802) a compound in an alkaline medium.

\subsubsection{Stating Facts, Purposes and Results}

The $\mathrm{x}+\mathrm{s}$ form (e.g., equals P32), BE(e.g., is $\mathrm{C} 313$ in [30] above, are G142) and negated MH-Type VBGs (e.g., do not protest $\mathrm{R} 687$ ) featured in the statement of facts. The to- non-finite VBG expressed purpose (e.g., to fill $\mathrm{C} 277$; wanted to give R316) and result (e.g., to give P28) at a ratio of 3:1. Progressive aspect (are dealing P416b) and modals of obligation (had to perform R699) further indicated purpose, while some copula verbs (became R166), passives (is created G160), and present (forms C118) and past (happened R348) tense forms, expressed result, or resulting temporary state. Excerpts [31]--[33] illustrate stating facts, purposes, and results respectively while [34] shows an uncommon use of the $\mathrm{x}+\mathrm{g}$ and $\mathrm{x}+\mathrm{n}$ (passive) non-finite forms to express result.

[31] GK123 There are (142) certain land features that the river creates (143). (cf. [27] above)

[32] CK257 Somebody said hydrogen is used to fill (282) balloons...

[33] PK264 Then the square root of their sum to give (287) us $\mathrm{f}_{2} \ldots \mathrm{K} 291$ This is (324a) the angle that $\mathrm{f}_{1}$ makes (324b) with resultant ...

[34] G547 The water now has been encamped on this section. K548 Then the river is moving fast again...

K550 Then leaving (598) this oxbow lake created (599).

\subsubsection{Assisting Recall}

Interrogative mood VBGs with verbs of cognition as head generally served the textual function of assisting recall as in [35] below.

[35] RK576 When the same people he fed, K577 you remember (718) the feeding of the $5000 ? \ldots$

\section{4.12 Declaring or Expressing Intention}

Some occurrences of let-imperative with me as intervening nominal complement, want-headed VBGs, and will-and $B E$ GOING TO-modified VBGs with intention as modal meaning, functioned to express intention. Here are examples.

[36] GK560 Let me give (610) you an assignment...K590 I want to reduce (642) the questions.

[37] CK331 I'm going to explain (361) that... K813 I will take (864) your attendance.

\subsubsection{Awakening Pupils' Consciousness}

Again, some VBGs marked for imperative mood with verbs of cognition as head (e.g., rememberR95\&P686, see P135, and think backP694 ( in [24] above ) functioned to awaken pupils' consciousness thus:

[38] RK75 Remember (95) there was a time when there was trouble in the Church...

\subsubsection{Giving Instructions, Guidelines or Directives}

To give instructions, guidelines or directives VBGs marked for imperative mood were generally employed (e.g., pair G636; let go on $\mathrm{C} 234$ ). However, there also occurred modality, meaning necessity ( e.g., have to change P474 in [20] above), compulsion ( e.g., are to tell R603) and possibility ( e.g., can use P147), present tense (e.g., use P220), and the $\mathrm{x}+\mathrm{g}$ (using P327) and to (to divide P150) non-finite forms. There is a sense in which the morphologically invariant $\mathrm{x}+$ $\mathrm{n}$ mathematics passives (raised, squared and divided) and their $\mathrm{x}+0$ present tense counterpart bracket can be regarded as directive verbs: They specified obligatory mathematical operations as squared P235 illustrates in [39] below.

[39] PK218 So let's find (233) the second force. K219 Once again you use (234) the same question (sic) all over $r$ squared (235)...K224a Now, when you are solving, K224b you ignore (241) the sign... K227 The moment you start solving the sign has to be ignored... (245) K241Now look at (258) the diagram once again...

[40] GK534 Yes, drop (579) the chalk there. K535 Thank you. K536 Move. K537 Go (582) and K538 listen (583).

\subsubsection{Suggesting Procedural Alternatives}

Procedural alternatives were suggested using can-modified VBGs with possibility as modal meaning, e.g., [41] PK303 You can also use (337) any one of the two angles, like I said earlier.(cf. CK756 You can also shake (799) it with alkaline pyrogallol)) 


\subsubsection{Affirming Previous Information}

Verbal groups marked for present tense served the textual function of affirming previously given information, a position, and the correctness of pupils' answers (e.g., have R265, mean P633, is G214). Where pupils' answers were wrong, however, verbs with negative prefixes (e.g., disagree P643) were employed.

[42] GK186 But now that ...the volume of water has increased. K187 Why? (R: Inaudible) K188 Exactly. K189 That's (214) the correct answer.

[43] PK571 No!, no!, no!, no! K572 You are giving me the distance apart. K573 I mean (633) the value of q...K579 So divide... K581 What do you have as our e one ? (R: Five times ten raised to power five)... K583 No. K584 I disagree (643) with that. K585 Thank you.

\subsubsection{Making Tentative Assumptions}

Verbal groups marked for imperative mood and present tense functioned to make tentative assumptions. They were headed by assume, call, say, believe and BE, as in let assume $\mathrm{G} 395$, let see $\mathrm{C} 139$, let call $\mathrm{P} 449$, believe (P405), and am (G255). Excerpts [44] and [45] illustrate further.

[44] GK28 Let say (30) this is (31) River Ola. K29 Then his child is (32) here now. K30 That is (33) Tokunbo ...

K31 Then the grandchild. K32 That is (34) Tolu here...K63 I assume (65) that that is a rough...sketch of West Africa.

[45] PK13 Now if we combine these two formulae, K14 call (18) this equation one and this equation two...

K373 But if you look at this diagram, K374 this is (404) east. K375 Believe (405). (R: Yes, sir)

\subsubsection{Exemplifying Concepts}

$B E$-headed VBGs (e.g., are P311, is C816) and VBGs marked for imperative mood (e.g., let take P44) were used in exemplification thus:

[46] GK219 Let me demonstrate (252) in a simple form. K220 Come (253) here. K221 Meanwhile, these are (254) my children, the tributaries. K223 I am (255) the main river. ( $B E$ is also assumptive here).

\subsection{Making inferences}

The verb lexemes mean, know, say, show, tell and BE, and some VBGs marked for modality (logical necessity), recurred in making inferences, as [47] illustrates.

[47] GK7 The river is flowing on laterite soil, K8 the lower land system then must be (8) on laterite.K9 If on the other hand it flows on a sandy soil, K10 it means (10) that the soil must be (11) sandy...

\subsubsection{Rationalising and 1ndicating Relationships}

Rationalisation and relationships were sometimes indicated by the same forms, with both textual functions sometimes fused in the same VBG ( e.g., must be G8, happens $\mathrm{P} 620$, determines $\mathrm{P} 619$, means $\mathrm{C} 51$, and is $\mathrm{P} 72$; see [48] below). However, there were strictly rationalising VBGs ( meansP690, isR372,G661: e.g., [49]); there were also strictly relational ones ( is going to attract P611, is G352, was R238, and happens G354, P730: e.g., [50]). Verbal groups indicating rationalisation, relationship and inference as textual functions were found to be lexically and morphologically identical; they were defined by the verb lexemes mean and $B E$, and the $\mathrm{x}+\mathrm{s}$ present tense form.

[48] RK288 And that is to tell us that a matter like the Holy Spirit cannot be purchased... K320 It just depends (419) on your relationship with God.

[49] CK286 Air is a mixture of gases... K287One of the gases that air has is what? K288 Nitrogen. K289 Which means (318) (inaudible) K290 It means (319) that you can use up twenty per cent of air. K291 The rest should be what? K292 Nitrogen ...K294 That is (323) why we have liquefaction as a very common way of manufacturing nitrogen.

[50] PK 25 We have [[ e equals (32) $\mathrm{q}_{1} \mathrm{q}_{2}$ all over pie Epsinum nought $r$ squared ]].

\subsubsection{Maintaining Discipline and Class Control}

With the notable exception of an instance of interrogative mood usage (GK385 Yes, Who is talking (425)?)), maintaining discipline and class control was achieved using VBGs marked for imperative mood (e.g., keep standing R157).

[51] CK359 Who are those people putting their heads on the table? ... K361 Keep (395) quiet and K362 listen (396). 


\subsubsection{Running Commentaries and Making Remarks}

No set of VBGs could be associated with running commentaries and making remarks. However, negative comments or remarks attracted negated VBGs (e.g., does not encourage C551). The verb thank expressed gratitude ([40]) and rejection ([43] ). It was also used to comment on the subject matter thus:

[52] RK107 Now we heard (136) that Philip went on to Samaria... K141 As he preached the word, K142 the power was demonstrated.K143 There were signs. K144 There were miracles... K147So they accepted his message. K148 Thank (191) God for that.

\subsubsection{Assigning Tasks}

Assigning tasks was achieved using VBGs marked for imperative mood. Quick tasks of synthesis or analysis attracted summarise $\mathrm{R} 21$, give $\mathrm{C} 507$, write $\mathrm{G} 611$ ); quick mental tasks saw the use of add $\mathrm{P} 168$, subtract $\mathrm{P} 169$, divide $\mathrm{P} 640$ ); and rigorous tasks were assigned using compare G 621 and interpretG625, among other verbs. Excerpt [53] illustrates.

[53] GK 560 Let me give you an assignment...K568b Enlarge (618) the rectangle shown on the map by two...

K570 Compare (621) the settlement of the eastern part to the western part. K571b Justify (623) with reasons five likely occupations that you can identify from the map. K572 Interpret (625) the scale into a statement... K575 Give (628) four roles of River Mamu for those that are living in the district.

\subsubsection{Expressing Necessity}

Modals and verbs of necessity indicated the textual function expressing necessity in the texts. Sample VBGs are need to find P255 and had to give R25 in [57] and [59] below. Excerpt [54] illustrates.

[54] PKK66 Look at the question again. K67 $\mathrm{Q}_{1}$ and $\mathrm{q}_{2}$ are known...K69 The value of distance is known.

K70 So plug in the value. K71 You should be able to get (91) the value of the electric field.

\subsubsection{Hypothesising}

Apart from the hypothetical modal would (cf. [55]), the let-imperative and the $\mathrm{x}+\mathrm{o}$ present tense form in conditional if clauses also expressed unreality. Here are illustrations.

[55] CK469 Once you are a chemist...K485 you are going to be a millionaire...K490 Someone would quickly want to ask (429) me that...K545 So let's say (590) in here you have the calcium oxide. K546 Is that okay?

[56] PK512 And, if you do (564) that... K513b you pick (566) the wrong answer. K513c You come (567) out of the exam hall. K514 You are (568) happy...

\subsubsection{Expressing Idiomatic Meanings}

Forty-eight forms expressed idiomatic meanings in the data. They were dominated by look at ( meaning examine and consider ) and talk about ( meaning discuss), which respectively accounted for $38 \%$ and $13 \%$ of the 176 VBG manifestations. All were particled HQ-Type and MHQ-Type VBGs, except RK72 Does it ring (92) a bell? Fifteen forms were subject-specific. Thus there were chemical idioms (e.g., takes in meaning receives), religious idioms (e.g., laid down meaning sacrificed), geographic idioms (e.g., swell up meaning become larger), and mathematical idioms in Physics (e.g., will cancel out, meaning "equal and opposed to something in force and effect"). The VBGs also served other purposes, such as introducing the lesson (e.g., want to look at R2), transiting from one segment of the lesson to another (e.g., let look at C194), enumerating points (e.g., have talked about C769), assisting recall (e.g., think back P694), and describing state (e.g., is cut off G445). As the examples show, VBGs expressing idiomatic functions were also marked for imperative mood, present tense, passive voice, and perfective aspect. Their semiotic versatility is illustrated here using comes in:

[57] PK239 You now need to find the resultant, K240 and that's where Pythagoras theorem comes in (257).

(Relevance)

[58] GK201 I said this is the river at the upper course...K204 Then, before you get to the middle stage, K205 this river comes in (233). (Joins/enters).

\subsubsection{Expressing Metaphorical Meanings}

Metaphorical functions were expressed using the past tense and particled VBGs in a variety of situations: narration, description, and explication of the subject matter. For example, will be taken up (C663) was a chemical metaphor for oxidise. Similarly, the dendritic drainage pattern was likened to a tree that has shed off (G47) its leaves. In Christian 
Religious Knowledge was, left, and planted and bowed, were respectively metaphors for Jesus, Jesus' death, and conversion to Christianity. Excerpt [59] illustrates.

[59] RK21 Because, before he left (24), K22 he had to give them this commission to do something...

K69 As they went along to preach the gospel, K70 they planted (88) the word in the hearts of the people... K168 He also bowed (215). K169 He believed ...K543 He was (672) really a sheep.

\section{Discussion of Findings}

Twenty-seven textual functions of the English VBG were identified in this study, and they were expressed by every manifest-able form of the VBG: its constituents, structure, systems, and meaning. Describing entities was the most profuse of the VBG's textual functions, and actions and processes were the most described. Some textual functions were restricted to particular texts; for instance, description of events and persons/people featured only in Christian Religious Knowledge. Similarly, not all the forms were associated with all the functions; $B E$ did not occur in the context of assisting recall, for example. Again, some forms were more restricted while others were freer. This is typical of perfective aspect, which mainly featured in enumeration of concluded processes, and VBGs marked for future tense or modality with intention as meaning, which were prominent in enumerating points to be discussed only. However, there was function overlap, in which the same textual function was indicated by multiple forms and the same form expressed multiple textual functions, in a true reflection of natural language dynamism.

Verbal groups marked for simple present tense indicated $73 \%$ of the textual functions ( including maintaining class control and discipline normally associated with imperatives). Its dominance relative to past (35\%) and future (14\%) tenses can be explained in terms of the nature of the data base. Only in Christian Religious Knowledge was the past tense form dominant. That tense forms expressed $78 \%$ of the textual functions is a strong indication of the significance of tense as a linguistic category for handling time relations in natural language. Lexical $B E$ 's prominence, which saw it manifest $60 \%$ of the textual functions (including an instance of admonitory order: RK450 Don't be (566) selfish)), cannot be attributed to its multiple forms alone (although it is quite easy to do so). There must be some semiotic property of this verb lexeme that makes it keep recurring in the language. This needs to be investigated. Although they accounted for only $8 \%$ of the data, verbal groups marked for imperative mood were remarkably versatile in that they featured in $32 \%$ of the twenty-seven textual functions, in addition to their primary semiotic role of giving orders.

\section{Conclusion}

The textual functions of the VBG described above are not exhaustive. More textual functions of the VBG may be discovered in other texts such as engineering, medicine, politics and journalism. This paper has however confirmed the fact that the formal features of the VBG group currently known grossly under-represent its textual functions in natural language. It also points to the need to break out of 20th century linguistic atomism to a holistic natural language linguistics with full focus on both form and situation which generates the textual functions. The criteria used for the textual functions are situation-induced elements of natural language and the fact that one form can perform different textual functions and that the same textual function can be performed by a variety of forms reinforce the fact that natural language situation cannot be ignored in the study of textual functions. As aptly demonstrated by $B E$, the study has further confirmed the lack of correspondence between grammatical form and its textual function.

\section{References}

Adejare, O. (in press). Natural language linguistics: Text, form and situation. Lagos: Difamo Books.

Adejare, R. A. (2010). The English verbal group in spoken instructional texts: A grammatical study of English as a second language in Nigeria. Ph.D. Thesis, University of Lagos.

Adejare, R. A. (2012). BE and HAVE in an aspect of Nigerian English usage. In P. A. Anyanwu, \& I. Obuasi (Eds.). Issues in Language and Human Development ( A Festschrift for Jerome Ikechukwu Okonkwo). ( pp. 65-76). Enugu: SAN Press Ltd.

Adejare, R. A. \& Adejare, O. (2006). Tertiary English grammar. (2nd ed.). Lagos: Difamo Books.

Atkinson, M., Kilby, D. \& Roca, I. (1982). Foundations of general linguistics. London: Allen \& Unwin.

Bloor, T. \& Bloor, M. (1995). The functional analysis of English: A Hallidayan approach. London: Arnold.

Fromkin, V. \& Rodman, R. (1983). An introduction to language. New York: Holt Rinehart \& Winston.

Hall, C.J. (2005). An introduction to language and linguistics: Breaking the language spell. London: Continuum. 
Halliday, M. A. K. (1961). Categories of the theory of grammar. WORD, 17/3 ( Rpt. as Bobbs-Merril series No Language 36): 241--92.

Halliday, M.A.K. \& Matthiessen, C.M.I.M. (2004). An introduction to functional grammar. (3rd ed.). London: Hodder Arnold.

Halliday, M.A.K., McIntosh, A. \& Strevens, P. D. (1964). The linguistic sciences and language teaching. London: Longman.

Hjelmslev, L. (1943). Prolegomena to a theory of language. (1969 ed.). (Translated by Francis J. Whitfield), Madison: The University of Wisconsin Press.

Lyons, J. (1977). Semantics.( 2 Volumes). Cambridge: Cambridge University Press.

Lyons, J. (1981). Language and linguistics: An introduction. Cambridge: Cambridge University Press.

Mey, J. L. (2001). Pragmatics : An introduction (2nd ed.). Malden: Blackwell Publishing.

Olaniyi, O. K. (2010). A pragmatic analysis of President Umar Yar Adua's inaugural speech of 29th May 2007. Journal of the Nigeria English Studies Association, 13/2, 50-67.

Opeibi, O. B. (2010). Language, globalization and democratic process: English in Nigerian political discourse. In O. Okoro (Ed.). Nigerian English in sociolinguistic perspectives: Linguistic and literary paradigms (A Festschrift in Honour of Funso Akere ). ( pp.241--60). Lagos: Pumark Nigeria Limited.

Palmer, F.R. (1987). The English Verb. (2nd ed.). London: Longman.

Quirk, R., Greenbaum, S., Leech, G. \& Svartvik, J. (1985). A Comprehensive grammar of the English language. London: Longman.

Saussure, F. de. (1974). Course in general linguistics. Edited by C. Bally \& A. Sechehaye in collaboration with A. Reidlinger. Translated from the French by W. Baskin with introduction by J. Culler. Glasgow: Fontana. 
Table 1. Textual functions and the verbal groups expressing them

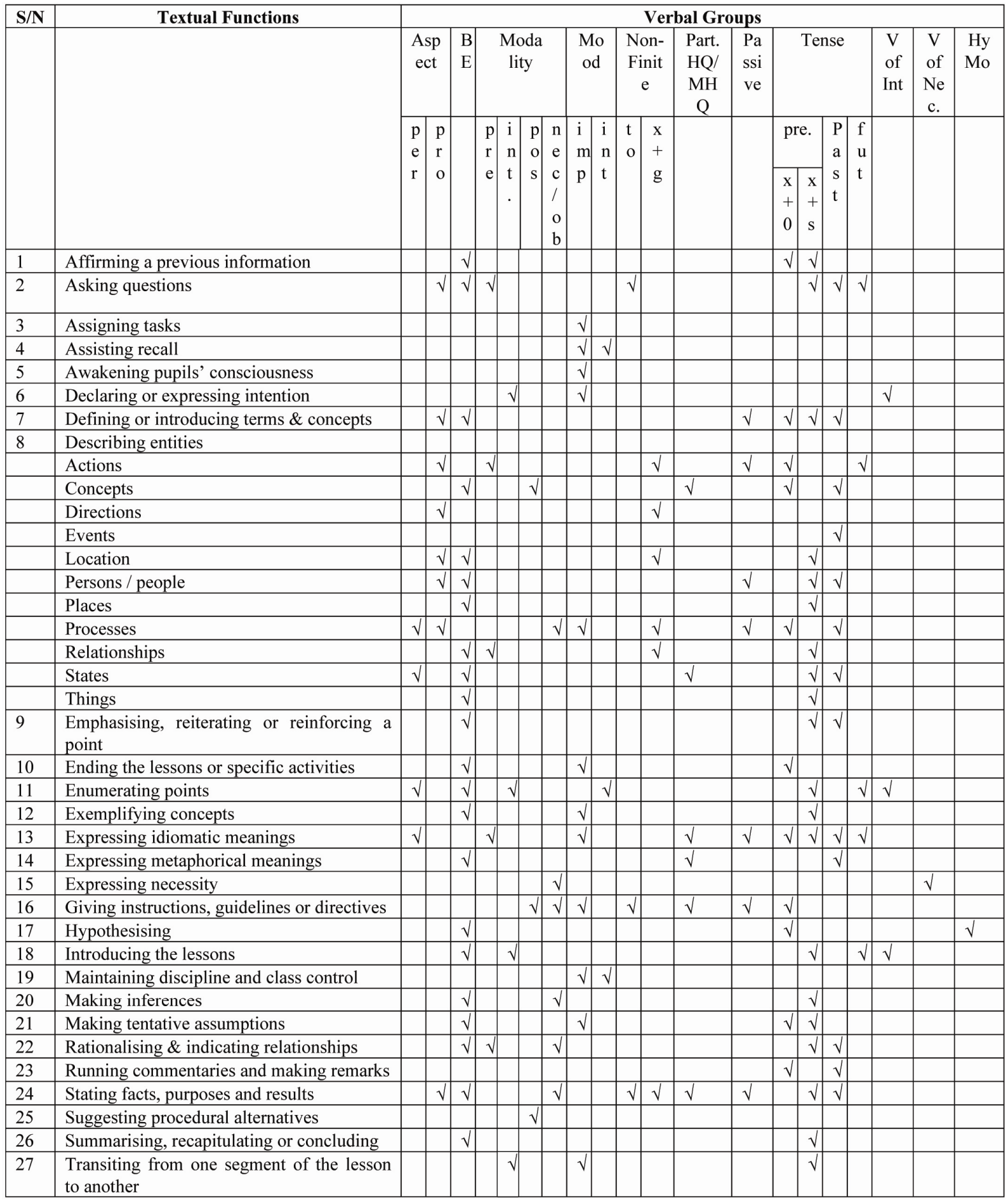

